DOI: https://doi.org/10.24867/13BE19Santrac

\title{
RAZVOJ MODELA UPRAVLJANJA PMSM ZA PRIMENU U POGONU ELEKTRIČNIH VOZILA U dSPACE/MICROLABBOX OKRUŽENJU
}

\section{DEVELOPMENT OF A DSPACE/MICROLABBOX BASED ELECTRIC DRIVE SYSTEM}

\author{
Ivana Santrač, Boris Dumnić, Fakultet tehničkih nauka, Novi Sad
}

\section{Oblast - ELEKTROTEHNIKA I RAČUNARSTVO}

Kratak sadržaj - U ovom radu testirana je aplikacija za upravljanje sinhronom mašinom sa stalnim magnetima $u$ pogonu električnih automobila. Korišćen je sistem hardvera u zatvorenoj petlji, pri čemu se mikrokontroler AURIX iz stvarnog pogona, proizvođača „Infineon Technologies AG", zamenio dSPACE sistemom, odnosno MicroLabBox hardverskim i softverskim okruženjem.

Ključne reči: sinhrona mašina sa stalnim magnetima, dSPACE, MicroLabBox

\begin{abstract}
In this paper the application for controlling a permanent magnet synchronous motor in automotive drive system is tested. Hadrware in the loop system is used, whereby the microcontroller AURIX from the real system, manufactured by, Infineon Technologies $A G$ “, is replaced with dSPACE system, MicroLabBox hardware and software environment.
\end{abstract}

Keywords: permanent magnet synchronous motor, dSPACE, MicroLabBox

\section{UVOD}

Električni automobili bili su popularni još između kasnih 1800-tih i ranih 1900-ih godina. Oni su u ovom periodu davali više komfornosti i jednostavnosti prilikom korišćenja, nego što je to bio slučaj sa automobilima koji su se pokretali fosilnim gorivima. Za njihovo pokretanje bilo je potrebno fizičko okretanje ručice. Međutim, pronalaskom elektromehaničkog pokretača SUS motora, kao i zbog razvoja ove vrste automobila, boljeg dometa i masovne proizvodnje, konvencionalni automobili su postali najzastupljeniji [1].

Ipak, povećavanjem broja automobila sa unutrašnjim sagorevanjem, dolazilo se sve više do njegovih negativnih strana. Prvo i najbitnije, kvalitet vazuha i nivo buke su se znatno pogoršali. Društvena svest o globalnom zagrevanju kao posledici ljudskog dejstva su se iz godine $u$ godinu sve više povećavali. Osim toga, dolazi se i do činjenice da su izvori nafte ograničeni, tako da je ponovo počelo da se traga za alternativom SUS motorima. Upravo zbog toga električna vozila ponovo su dospela u centar pažnje [2].

\section{NAPOMENA:}

Ovaj rad proistekao je iz master rada čiji mentor je bio dr Boris Dumnić, van. prof.

\section{OPIS HARDVERA I SOFTVERSKOG OKRUŽENJA}

Simulacija sa hardverom u petlji (eng. Hardware in the loop - HIL) je tehnika koja se koristi u razvoju i testiranju kompleksnih ugrađenih sistema (eng. Embeded systems) u realnom vremenu. Ovaj tip simulacija predstavlja efikasnu platformu zbog toga što se u samo testiranje dodaje kompleksost postrojenja koje se kontroliše. Sistem koji je ugrađen se ispituje u interakciji upravo sa ovom simulacijom. Prilikom simulacija sa hardverom u petlji koriste se matematički algoritmi koji oponašaju rad postrojenja $u$ realnom vremenu i pri realnim uslovima, sa ciljem predviđanja njegovog ponašanja [3].

HIL aplikacije za testiranje u fazi dizajniranja mogu biti klasifikovane kao testiranje u otvorenoj petlji (eng. Open Loop Testing) i testiranje u zatvorenoj petlji (eng. Closed Loop Testing). Prilikom testiranja u otvorenoj petlji, koriste se jednostavniji ulazno/izlazni (I/O) model bez povratne sprege, kao što je to prikazano na slici 2.1 .

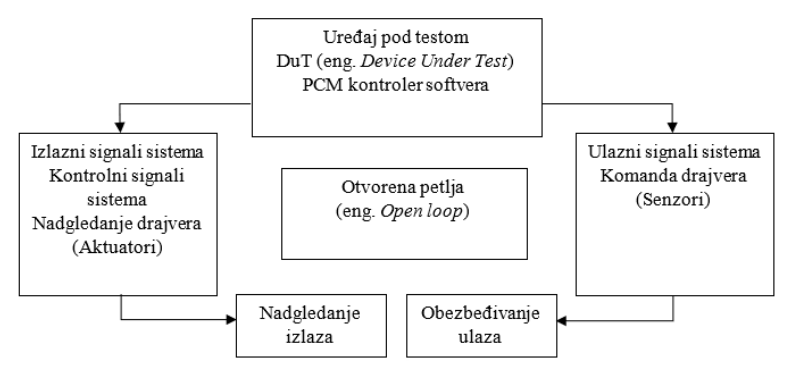

Slika 2.1 HIL aplikacija u otvorenoj petlji [4]

Sa druge strane, testiranje u zatvorenoj petlji zahteva kompletan model sa odgovarajućim izlaznim odzivima sistema, kao što je prikazano na slici 2.2. Prilikom ovakvog testiranja komandne, odnosno referentne vrednosti se koriste za pokretanje samog modela. Izaz modela jeste mehanička ili električna jedinica i ona je dalje korišćena za proračun ponašanja i dinamičkih odziva senzora [4].

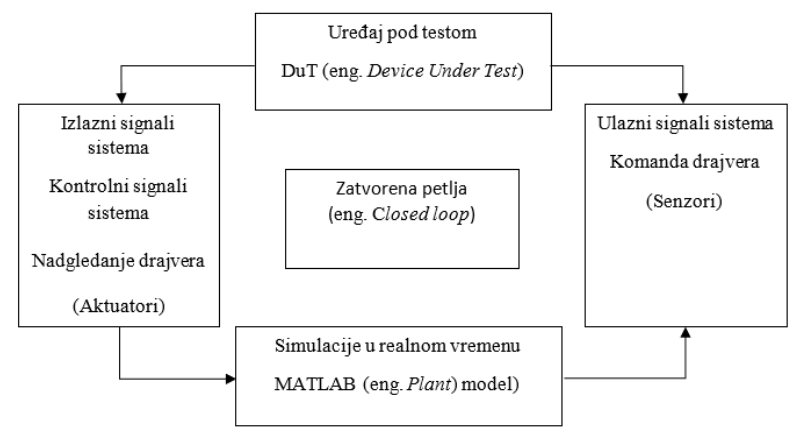

Slika 2.2 HIL aplikacija u zatvorenoj petlji [4] 


\subsection{Opis $d S P A C E / M i c r o L a b B o x$ okruženja}

DSPACE je sistem za simulacije u realnom vremenu baziran na MATLAB-u/Simulink-u i predstavlja softversku i hardversku platformu za razvoj i testiranje kontrolnih sistema. dSPACE sistem predstavlja platformu za aplikacije bazirane na HIL simulacijama u realnom vremenu, pri čemu su ispunjeni različiti zahtevi kontrole, kao što su podešavanje parametara, radno okruženje samog kontrolera u realnom vremenu, i drugi [5].

MicroLabBox je hardverski uređaj, koji je podržan od strane obimnog dSPACE softverskog paketa, uključujući Real-Time Interface (RTI) za Simulink, za modele bazirane na ulazno/izlaznoj integraciji i eksperimentalni softver ControlDesk, koji obezbeđuje pristup aplikacijama u realnom vremenu tokom trajanja simulacija putem grafičkih instrumenata [6].

U ovom radu korišćena je spring-cage panelna varijanta prikazana na slici 2.3 .

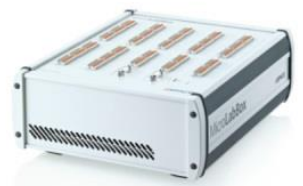

Slika 2.3 Izgled MicroLabBox uređaja [6]

\subsection{Opis razvojnog okruženja}

Kontrolni sistem sinhronog motora sa stalnim magnetima (eng. Permanent Magnet Synchronous Machine - PMSM), baziran na eksperimentu u dSPACE-u, prikazan je na slici 2.4.

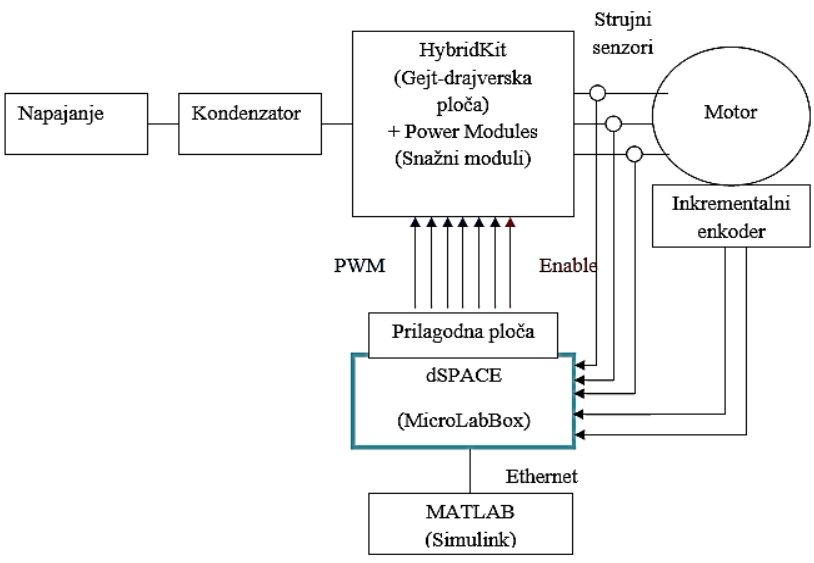

Slika 2.4 PMSM kontrolni sistem baziran na dSPACE razvojnom okruženju

Na slici 2.5 prikazana je postavka celokupnog sistema za testiranje u laboratoriji. Komponente koje su prikazane na slici 2.5 su sledeće: 1 - računar, 2 - kabel za uspostavljanje Ethernet veze, 3 - MicroLabBox, prilagona ploča, 5 i 6 HybirdKit (gejt-drajverska ploča) i HybridPACK ${ }^{\mathrm{TM}}$ Drive moduli (snažni moduli), pri čemu su obe ploče proizvođača „Infineon Technologies AG“, 7 - „film kondenzator“ za HybridPACK $^{\mathrm{TM}}$ IGBT module, 8 - strujni LEM senzori, oznake HC5F400-S, 9 -Inkrementalni enkoder „Baumer“, oznake GI341, 10 - izvor napajanja prilagodne ploče, 11 izvor napajanja povezan sa kondenzatorom, 12 - PMSM motor proizvođača „Dunkermotoren“, oznake BG 75x50.

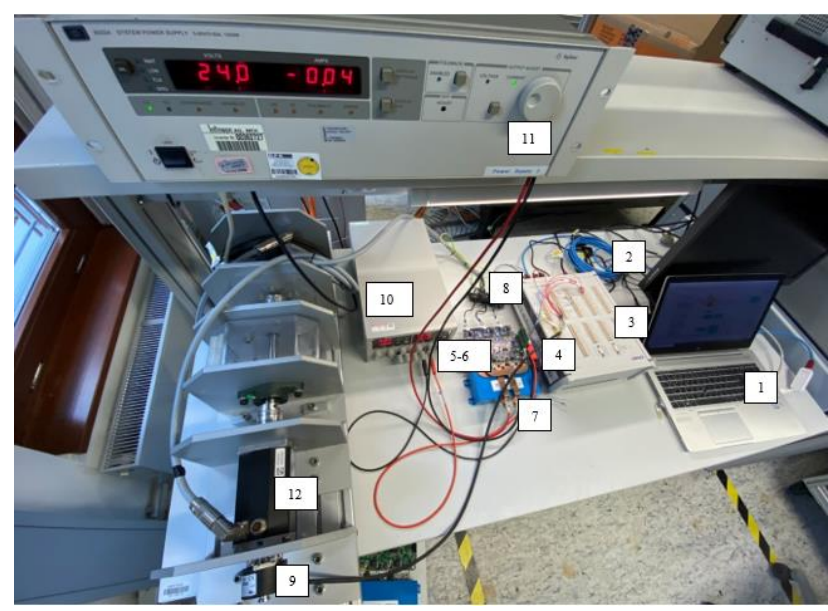

Slika 2.5 Postavka sistema za testiranje u laboratoriji

\section{RAZVOJ MATEMATIČKOG MODELA}

Prilikom izrade samog modela električne mašine, poželjno je uzeti u obzir sve osobine sistema koje mogu uticati na njegovo ponašanje. Sa druge strane, glavna prednost modelovanja jeste pojednostavljenje celokupnog modela i zanemarivanje elemenata koji nisu bitni za fizički proces [7].

\subsection{Matematički model u trofaznom domenu}

Jednačine naponske ravnoteže PMSM predstavljene su sledećim relacijama [7]:

$$
\left[\begin{array}{l}
u_{s a} \\
u_{s b} \\
u_{s c}
\end{array}\right]=\left[\begin{array}{ccc}
R_{a} & 0 & 0 \\
0 & R_{b} & 0 \\
0 & 0 & R_{c}
\end{array}\right]\left[\begin{array}{l}
i_{s a} \\
i_{s b} \\
i_{s c}
\end{array}\right]+\frac{d}{d t}\left[\begin{array}{l}
\psi_{s a} \\
\psi_{s b} \\
\psi_{s c}
\end{array}\right]
$$

Naponi $\mathrm{u}_{\mathrm{sa}}, \mathrm{u}_{\mathrm{sb}} \mathrm{i} \mathrm{u}_{\mathrm{sc}}$ predstavljaju fazne napone na priključcima statora, $i_{s a}, i_{s b} i i_{s c}$ struje kroz statorske namotaje, dok $R_{a}, R_{b}$ i $R_{c}$ predstavljaju otpornosti statorskog namotaja i za njih važi da imaju jednake vrednosti pod uslovom da je mašina simetrična.

Jednačine kojima se opisuju fluksni obuhvati statora [7]:

$$
\left[\begin{array}{l}
\psi_{s a} \\
\psi_{s b} \\
\psi_{s c}
\end{array}\right]=\left[\begin{array}{lll}
L_{a a} & L_{a b} & L_{a c} \\
L_{b a} & L_{b b} & L_{b c} \\
L_{c a} & L_{c b} & L_{c c}
\end{array}\right]\left[\begin{array}{l}
i_{s a} \\
i_{s b} \\
i_{s c}
\end{array}\right]+\left[\begin{array}{l}
\psi_{m a} \\
\psi_{m b} \\
\psi_{m c}
\end{array}\right]
$$

Jednačina elektromagnetnog momenta [7]

$$
T_{e}=\frac{1}{2} p\left[i_{s}\right]^{T} \frac{d[L]}{d t}\left[i_{s}\right]=\frac{p}{2}\left[i_{s a} i_{s b} i_{s c}\right]\left[\begin{array}{lll}
\frac{L_{a a}}{d t} & \frac{L_{a b}}{d t} & \frac{L_{a c}}{d t} \\
\frac{L_{b a}}{d t} & \frac{L_{b b}}{d t} & \frac{L_{b c}}{d t} \\
\frac{L_{c a}}{d t} & \frac{L_{c b}}{d t} & \frac{L_{c c}}{d t}
\end{array}\right]
$$

pri čemu je sa $\mathrm{p}$ označen broj pari polova. Na kraju se dolazi do Njutnove jednačine rotacionog kretanja [7]:

$$
J \frac{d \omega_{r}}{d t}=T_{e}-T_{m}
$$

pri čemu je sa $\mathrm{J}$ označen momenat inercije rotora, sa $\mathrm{T}$ ukupni momenat tereta, a sa $\omega_{r}=d \theta_{r} /$ dt ugaona brzina rotora.

\subsection{Matematički model u dvofaznom stacionarnom, $\alpha \boldsymbol{\beta}$ domenu}

Prva transformacija koja se izvršava jeste Klarkina transfomacija (eng. Clarke), odnosno transformacija rasprezanja. Prilikom ove transformacije dolazi se do prenosa trofaznih veličina iz stacionarnog abc domena $u$ stacionarni dvofazni $\alpha \beta$ domen. Klarkina transformacija se može opisati sledećom relacijom [7]:

$$
V_{\alpha \beta}=C \cdot V_{a b c}
$$


Jednačine naponske ravnoteže [7]:

$$
\left[\begin{array}{l}
u_{s \alpha} \\
u_{s \beta}
\end{array}\right]=\left[\begin{array}{cc}
R_{s} & 0 \\
0 & R_{s}
\end{array}\right]\left[\begin{array}{l}
i_{s \alpha} \\
i_{s \beta}
\end{array}\right]+\frac{d}{d t}\left[\begin{array}{l}
\psi_{s \alpha} \\
\psi_{s \beta}
\end{array}\right]
$$

Jednačine fluksnih obuhvata [7]:

$$
\left[\begin{array}{l}
\psi_{s \alpha} \\
\psi_{s \beta}
\end{array}\right]=\left[\begin{array}{cc}
L_{s r} & 0 \\
0 & \left.L_{s r}\right)
\end{array}\right]\left[\begin{array}{l}
i_{s \alpha} \\
i_{s \beta}
\end{array}\right]+\psi_{P M}\left[\begin{array}{c}
\cos \left(\theta_{P M}\right) \\
\sin \left(\theta_{P M}\right)
\end{array}\right]
$$

pri čemu je $L_{S R}=\frac{L_{d}+L_{q}}{2}$.

\subsection{Matematički model u dvofaznom rotacionom, dq domenu}

Nakon što je obaveljena Klarkina transformacija, na red dolazi transformacija rotacije, odnosno Parkova tranformacija. Prilikom ove transformacije dvofazna veličina iz stacionarnog $\alpha \beta$ domena prenosi se na dvofazni sinhrono rotirajući dq sistem. Osnovni cilj ove transformacije jeste da se obezbedi nezavisnost matrice induktivnosti od ugaonog položaja rotora $\theta_{R}$, odnosno vremena. Ova transformacija opisana je sledećom relacijom [7]:

$$
V_{d q}=V_{\alpha \beta} e^{-j \theta_{d q}}
$$

Primenom Parkove transformacije jednačine naponske ravnoteže dobijaju sledeći oblik [7]:

$$
\left[\begin{array}{l}
u_{s d} \\
u_{s q}
\end{array}\right]=\left[\begin{array}{cc}
R_{s} & 0 \\
0 & R_{s}
\end{array}\right]\left[\begin{array}{l}
i_{s d} \\
i_{s q}
\end{array}\right]+\frac{d}{d t}\left[\begin{array}{l}
\psi_{s d} \\
\psi_{s q}
\end{array}\right]+\omega_{r}\left[\begin{array}{cc}
0 & -1 \\
1 & 0
\end{array}\right]\left[\begin{array}{l}
\psi_{s d} \\
\psi_{s q}
\end{array}\right]
$$

Jednačine fluksnih obuhvata [7]:

$$
\begin{aligned}
& \psi_{s d}=L_{s} i_{s d}+\psi_{P M} \\
& \psi_{s d}=L_{s} i_{s d}+\psi_{P M}
\end{aligned}
$$

Jednačina za moment koji proizvodi PMSM [7]:

$$
m=\frac{3}{2} P \psi_{P M} i_{s q}
$$

\subsection{Vektorsko upravljanje sinhronom mašinom}

Vektorsko upravljanje (eng. Field oriented control) ima cilj nezavisnog upravljanja magnetnim poljem i momentom, kontrolišući d i q komponente struje. Osnova prednost ove tehnike jeste brzi odziv i mala talasnost momenta [8]. Na slici 3.1 prikazan je blok dijagram standardnog upravljanja pogonom sa sinhronim motorom sa stalnim magnetima.

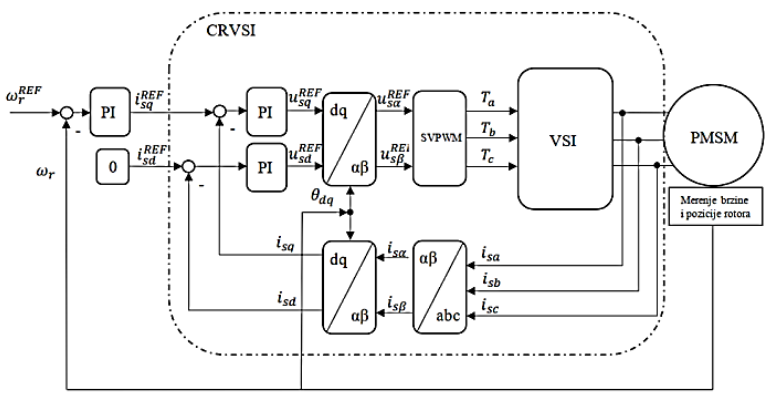

Slika 3.1 Blok dijagram upravljanja PMSM [7]

\section{MODEL U MATLAB-U (SIMULINK-U)}

$\mathrm{Na}$ slici 4.1 prikazan je model vektorskog upravljanja PMSM za izvršavanje u realnom vremenu, realizovan $u$ MATLAB/Simulink-u. Narandžastom bojom označena je brzinska petlja, dok je crnom bojom uokviren deo koji se odnosi samo na strujnu petlju.

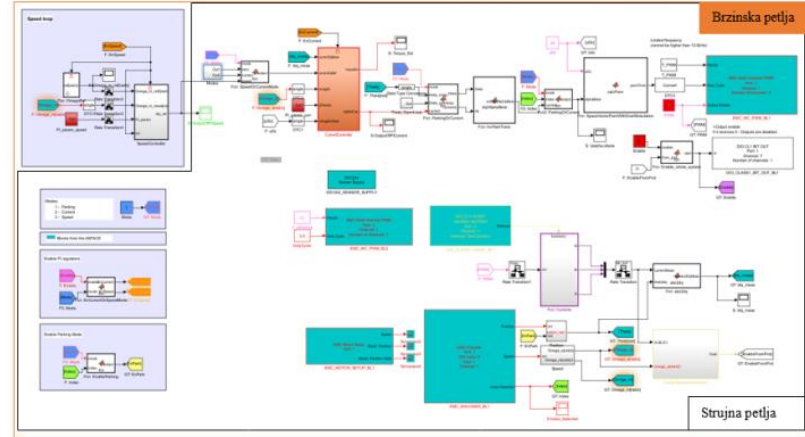

Slika 4.1 Model vektorskog upravljanja sa PMSM u MATLAB-u/Simulink-u

Implementirana su 3 režima rada sa PMSM i to: parking, strujni režim i brzinski režim.

\section{REZULTATI EKSPERIMENTA}

U ovkviru ovog rada, na prethodno opisanoj postaci za testiranje PMSM u laboratoriji, izvršeno je niz eksperimenata. Upravljanje tokom eksperimenta, pokretanje kao i zaustvljanje eksperimenta izvršeno je softverskim alatom ControlDesk. U eksperimentu čiji će rezultati biti prikazani u nastavku izvršeno je pokretanje PMSM a nakon toga je izvršena promena mehaničke brzine obrtanja mašine sa $300 \mathrm{o} / \mathrm{min}$ na $500 \mathrm{o} / \mathrm{min}$ i zatim na 100 o/min. Na slici 5.1 prikazana je vremenska zavisnost faktora ispune, gde se sa povećanjem brzine povećava i vrednost faktor ispune.

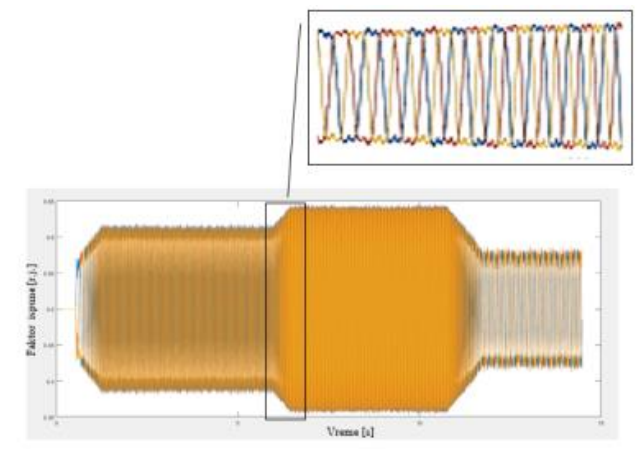

Slika 5.1 Vremenska zavisnost faktora ispune

Na slici 5.2 prikazane su struje sve tri faze tokom ovog eksperimenta, Može se videti da su fazne struje PMSM pomerene za $120^{\circ}$. Takođe, kao šo je i očekivano sa povećanjem brzine mašine povećava se i amplituda struje koju mašina vuče iz izvora napajanja.

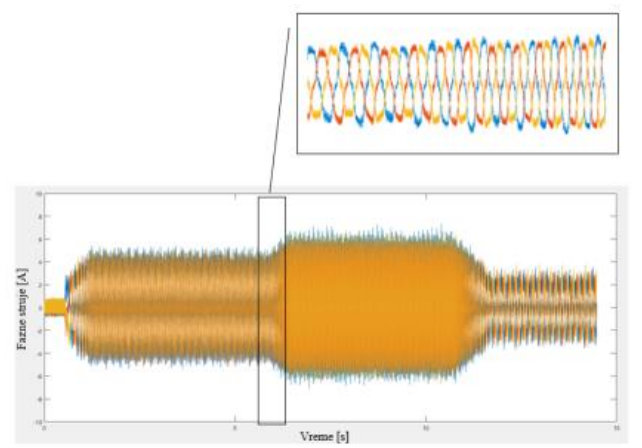

Slika 5.2 Vremenska zavisnost faznih struja 
Na slici 5.3 prikazana je podužna komponenta struje statora (Id), dok je na slici 5.4 prikazana poprečna komponenta (Iq). Može se videti da je podužna komponenta tokom čitavog eksperimenta ostala na nultoj vrednosti, dok se poprečna komponenta menjala u skladu sa promenom brzine.

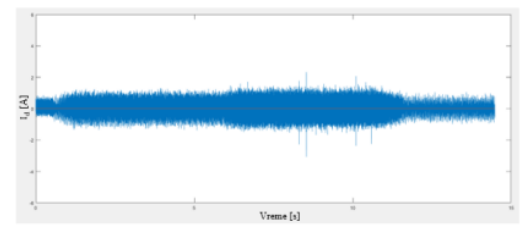

Slika 5.3 Vremenska zavisnost podužne (Id) komponente struje statora

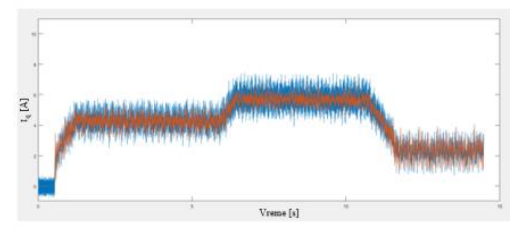

Slika 5.4 Vremenska zavisnost poprečne (Iq) komponente struje statora

Na slici 5.5 prikazana je mehanička brzina u o/min, dok je na poslednjoj slici prikazan ugao $\theta$. Povećanjem brzine povećava se frekvencija, pa je samim time i učestalost ugla $\theta$ veća.

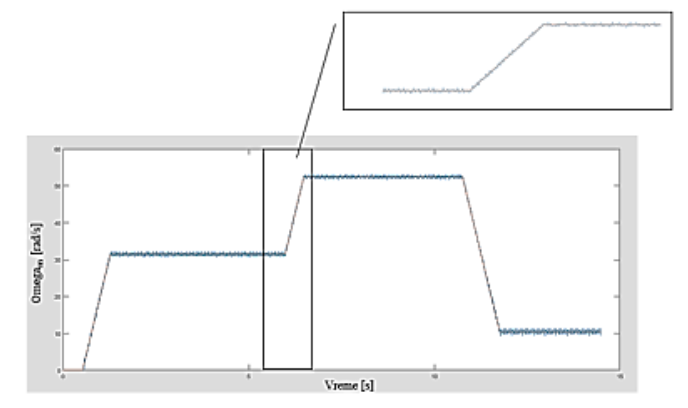

Slika 5.5 Vremenska zavisnost mehaničke brzine PMSM

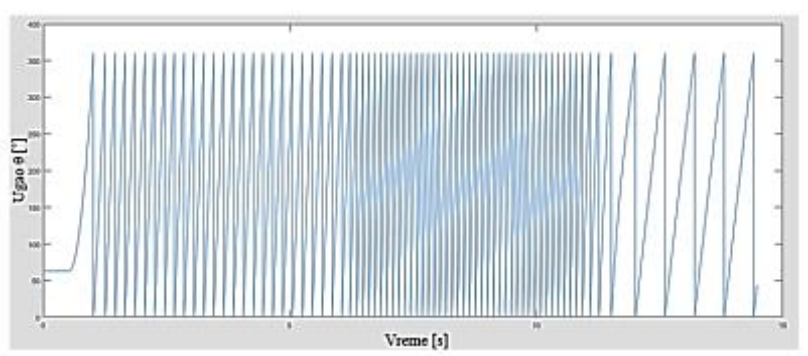

Slika 5.6 Vremenska zavisnost ugla $\theta$

\section{ZAKLJUČAK}

Razvoj i testiranje kontrolnih algoritama za upravljanje elektromotornim pogonima zahteva upotrebu savremenih softverskih rešenja i emulacionih kao i eksperimentalnih tehnika. Celokupan sistem hardvera u petlji, prikazan $\mathrm{u}$ ovom radu, praktično je implementiran i testiran $u$ laboratoriji tima za istraživanje i razvoj, u automobilskom sektoru, kompanije „Infineon Technologies AG“. Rezultati dobijeni simulacijama odgovaraju osobinama koje su karakteristične za upravljanje sihnronim motorom sa stalnim magnetima i samim time potvrđuju tačnost algoritma upravljanja koji je razvijen u ovom radu i testiran. Iako se u rezulatima vide šumovi u merenim veličinama struje i brzine obrtanja, ostvaren je sasvim zadovoljavajući kvalitet upravljanja PMSM dok su ovi šumovi direktna posledica korišćenja strujnih senzora za prilično veliki opseg struja od $\pm 400 \mathrm{~A}$, dok su vrednosti merenih struja svega par A.

\section{LITERATURA}

[1] ,Global EV Outlook”, https://www.iea.org/reports [2] „Istorija hibridnih i električnih vozila od prvih automobila do danas", https://www.energetskiportal.rs

[3] "Hardware-in-the-Loop" ttps://www.ni.com/en-rs/

[4] S. Nabi i M. Balike, Visteon Corporation, J. Allen i K. Rzemien, dSPACE Inc, "An overview of hardware-inthe-Loop testing systems at Visteon", 2014

[5] Q. Yang i Z. Kang, “ Study on space vector PWM technology of PMSM control system based on dSPACE", IEEE International Conference on Information and Automation (ICIA), str. 579

[6] "dSPACE web page”, //https:dspace.com/

[7] M. Gecić, „Energetski efikasno digitalno upravljanje sinhronim motorm sa stalnim magnetima pri velikim brzinama obrtanja“, doktorska disertacija, Fakultet tehničkih nauka, Novi Sad, 2016.

[8] D. Vindel, S. Haghbin, A. Rabiei, O. Carlson, R. Ghorbani, "Field oriented control of a PMSM drive system using the dSPACE controller", IEEE International Electric Vehicle Conference (IEVC)

\section{Kratka biografija:}

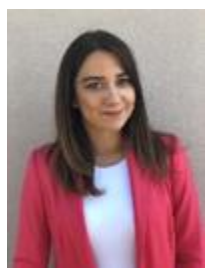

Ivana Santrač rođena je u Vršcu 1995. godine. Master rad na Fakultetu tehničkih nauka iz oblasti Elektrotehnike i računarstva - energetska elektronike i električne mašine odbranila je 2021. godine.

kontakt: santracivana@gmail.com

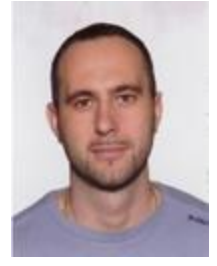

Boris Dumnić rođen je u Bileći 1976. god. Diplomirao je 2003. Godine na Fakultetu tehnilkih nauka u Novom Sadu Elektrotehnika i računarstvo. Od 2004. godine zaposlen je na Fakultetu tehničkih nauka u Novom Sadu. Magistarski rad je odbranio 2007. godine, a 2013. godine je odbranio i doktorsku tezu. Oblast interesovanja su mu električne mašine, pogoni, energetska elektronika i obnovljivi izvori električne energije. 